Int. J. Electrochem. Sci., 11 (2016) 2638 - 2649

International Journal of

ELECTROCHEMICAL

SCIENCE

www.electrochemsci.org

\title{
Simultaneous Electrochemical Determination of Dopamine, Uric acid, Tryptophan on Electropolymerized Aminothiazole and Gold nanoparticles Modified Carbon nanotubes Modified Electrode
}

\author{
Cheng Yu Yang, Shen-Ming Chen* , Selvakumar Palanisamy
}

Electroanalysis and Bio electrochemistry Laboratory, Department of Chemical Engineering and Biotechnology, National Taipei University of Technology, No.1, Section 3, Chung-Hsiao East Road, Taipei 106, Taiwan (ROC)

*E-mail: smchen78@ms15.hinet.net

doi: $10.20964 / 110402638$

Received: 21 December 2015 / Accepted: 7 February 2015 / Published: 1 March 2015

In the present work, a multifunctional biosensor was developed for the simultaneous determination of dopamine (DA), uric acid (UA) and tryptophan (Try) using 2-amino-thiazole (AT)/gold nanoparticles (AuNPs) functionalized multiwalled carbon nanotubes ( $f$-MWCNT) modified electrode. The $f$ MWCNT/AuNPs-AT composite modified glassy carbon electrode (GCE) was prepared by electrodeposition of AT and followed by electrodeposition of AuNPs and drop casting of $f$-MWCNT on GCE. The formation of the composite was confirmed by atomic force microscopy, scanning electron microscopy and electrochemical studies. The $f$-MWCNT/AuNPs-AT modified GCE exhibits good electrocatalytic ability for the simultaneous determination of DA, UA and Try. Cyclic voltammetry and linear sweep voltammetry were used for simultaneous and selective determination of DA, UA and Try. Moreover, the modified electrode also provides good sensitivity and selectivity for the determination of DA, UA and Try.

Keywords: Dopamine, uric acid, tryptophan, carbon nanotubes, gold nanoparticles, electrocatalysis, multifunctional biosensor.

\section{INTRODUCTION}

\section{$\underline{\text { FULL TEXT }}$}

(C) 2016 The Authors. Published by ESG (www.electrochemsci.org). This article is an open access article distributed under the terms and conditions of the Creative Commons Attribution license (http://creativecommons.org/licenses/by/4.0/). 